\title{
Morphological Characteristics and In Situ Auxin Production during the Histogenesis of Staminate Flowers in Precocious Walnut
}

\author{
Ying Gao, Hao Liu, and Dong Pei ${ }^{1}$ \\ State Key Laboratory of Tree Genetics and Breeding, Research Institute of Forestry, Chinese \\ Academy of Forestry, Beijing 100091, P.R. China
}

\begin{abstract}
AdDitional INDEX words. anatomical, differentiation, immunohistochemical localization, indole acetic acid Juglans regia

ABstract. Monoclonal anti-indole acetic acid antibodies were used to monitor the temporal and spatial pattern of auxin during staminate flower differentiation in walnut (Juglans regia) cultivars Liaoning 1 and Liaoning 3. The relationship between morphological characteristics and histological structure was established. Seven stages of differentiation were recognized based on the visibility and color of the squama, bract, perianth, and rachis as follows: Stage 1, several bract primordia were present in the squama with catkins protruding from the squama as the only externally visible portion of the floret (Stage 1); the bract became externally visible, and the floret, perianth, and stamen primordia formed basipetally (Stage 2); the length of catkins were elongated, only bracts visible and getting brown (Stage 3); the bracts were brown and wrapped tightly, cellular specialization occurred to form a central core containing reproductive cells and tapetal cells that differentiated (Stage 4); the perianth became visible externally, reproductive cells and tapetal cells separated from the exterior layers of the anther wall (Stage 5); the anther walls were reduced to two cell layers (epidermis and endothecium) as the anthers became visible and matured (Stage 6); and the anther turned black, dehisced, and released its pollen grains (Stage 7). The histological differentiation of the flowers was related to auxin. The auxin signal was strongest in the shoot apical meristem (SAM) during bract primordia differentiation; thus, the SAM may be a site of auxin production. When the floral organs began centralized differentiation, auxin was distributed mainly in the differentiating tissues. Our findings indicate that a high level of auxin may strongly affect morphogenesis. Additionally, the tapetal and reproductive cells that arise during cellular specialization may be important for auxin production. The distribution of auxin was centralized in germ pores at the pollen grain surface, indicating that a high level of auxin induces pollen germination.
\end{abstract}

The anatomy of walnut staminate inflorescences from the time of initiation until budbreak has been studied by several investigators (Li et al., 2011; Luza and Polito, 1988). The consensus among these studies is that the development of a walnut staminate inflorescence requires $\approx 1$ year from the time of initiation to maturation. However, the differentiation course varies by cultivar and climate (Polito and Katherine, 1997; Zhang et al., 1995). Marker characteristics should be linked genetically to the process of differentiation to ensure stability in the face of climatic variation. Attempting to project a marker event may be required. Markers that are easily duplicated and measured can be used to track events during histogenesis and enable comparisons of different studies. Morphological features that can be used as indicators of developmental stage have been identified in various plants. For example, flower bud development in Cyclocarya paliurus can be defined based on floret size, anther color, and characteristics of the stigma ( $\mathrm{Fu}$ et al., 2011), whereas the emergence of a globular embryo is a reliable indicator of the beginning of tissue differentiation in pineapple [Ananas comosus (He et al., 2012)]. Evaluating development based on morphology is easy, but the relationship between the morphology and physiology of walnut catkins has not been established.

Received for publication 25 Oct. 2013. Accepted for publication 31 Dec. 2013. This work was supported by the Scientific and Technological Support of China (the research and demonstration of walnut and pecan efficient production key technology, No. 2013BAD14B01) and the National Natural Science Foundation of China (No. 31171933).

${ }^{1}$ Corresponding author. E-mail: peigu@caf.ac.cn.
Auxin is an essential hormone that has been implicated in many aspects of plant growth and development (Woodward and Barrel, 2005), and the relationship between auxin and flower formation has been extensively studied (Aloni et al., 2006; Cheng and Zhao, 2007; Jiménez, 2005; Marleen and Eva, 2012). Auxin is considered to be a key regulator of floral development, but the exact role of auxin in this process has only recently come to be well understood (Chandler, 2011). Valentina et al. (2008) demonstrated that auxin synthesized in anthers coordinates anther dehiscence and pollen maturation, whereas auxin transport contributes to the independent regulation of preanthesis filament elongation; hence, auxin is an important physiological regulator of staminate flower differentiation. Using immunologic techniques, auxin can be detected in situ in plant tissues. Indeed, immunohistochemical localization studies have been performed in maize [Zea mays (Vysotskaya et al., 2007)], arabidopsis [Arabidopsis thaliana (Aloni et al., 2003)], the shoot apices of strawberry [Fragaria $\times$ ananassa (Hou and Huang, 2005)], and hybrid poplar $[$ Populus alba $\times(P$. davidiana $\times$ P. simonii $) \times P$. tomentosa (Dong et al., 2012)].

Previous attempts have been made to establish the relationships among the morphological characteristics, physiology, and histogenesis of staminate flowers in walnut (Vladimra and Sladky, 1971; Yates and Sparks, 1992). The application of exogenous hormones could transform the staminate primordia into vegetative buds. These findings comprise a first step toward elucidating the mechanism of walnut staminate flowering and the role of hormones in walnut catkin formation. Additionally, they have created a foundation for studying the regulation of staminate flowering in walnut. The results of this study also 
have significance for dioecious species, in which male and female individuals produce unisexual flowers and are characterized by sexual dimorphism (Cristiana Moliterni et al., 2004).

In this present study, an anti-indole acetic acid (IAA) monoclonal antibody was used to detect and localize endogenous IAA during walnut flower differentiation using an immunochemical approach. We provide a substantial base for the further research on the mechanism of IAA action during staminate flower bud differentiation.

\section{Materials and Methods}

Plant material. We used the protandrous walnut cultivars Liaoning 1 and Liaoning 3 . Trees were 7 to 15 years of age in Hebei province and characterized by steady reproductive growth and moderate vigor. During staminate flower differentiation (Apr. 2010 to Apr. 2012), we sampled 20 staminate flowers from the midpoint of catkin development for anatomical observation and IAA immunohistochemical study.

MORPHOLOGICAL OBSERVATION OF CATKIN DIFFERENTIATION. Branches with catkins were taken to the laboratory. We used a vernier caliper to measure the length of the 20 catkins and excised florets under the lens $(\times 2)$. Photographs were taken by digital camera (FinePix S602; Fujifilm, Tokyo, Japan) and on a microscope $(\times 4)$ (SZ61-SET; Olympus, Tokyo, Japan) (Fig. 1).

Anatomical observation of Catkin differentiation. Excised samples were immediately fixed in freshly prepared $5 \%$ formaldehyde, $5 \%$ acetic acid, $70 \%$ ethanol for at least $24 \mathrm{~h}$, dehydrated through a series of ethanol steps $(70 \%, 85 \%, 95 \%$, $100 \%$ ), cleared in dimethylbenzene, and embedded in paraffin. Vertical and cross-sections of $8-\mu \mathrm{m}$ thickness were cut with a rotary microtome (RM 2125RT; Leica, Wetzlar, Germany), transferred to glass slides, dried overnight, and stained with safranin-fast-green (Sigma, St. Louis, MO). Photographs were taken on a microscope (BX41-12P02; Olympus). Three replicates were used for each sampling (Fig. 2).
IN SITU ANALYSIS OF IAA. Excised samples were immediately fixed in a $2 \%(\mathrm{w} / \mathrm{v})$ aqueous solution of 1-ethyl-3-(3dimethylaminopropyl)-carbodiimide [EDC (Sigma)] for $2 \mathrm{~h}$ under vacuum, post-fixed overnight in a solution containing $4 \%$ paraformaldehyde and $2.5 \%$ glutaraldehyde at $4{ }^{\circ} \mathrm{C}$, and rinsed in phosphate buffer $(0.2 \mathrm{M} \mathrm{pH} 7.2)$ followed by dehydration in a graded ethanol series.

For immunohistochemical observation by light microscopy, samples were embedded in paraffin and sectioned to $8-\mu \mathrm{m}$ thickness (vertical sections and cross-sections). Sections were transferred onto glass slides. After overnight drying at $45^{\circ} \mathrm{C}$, sections were deparaffinized with xylene and hydrated in an ethanol/water series. The procedure for the immunolocalization of IAA followed Holgate et al. (1983) with some modifications: slides were incubated for $30 \mathrm{~min}$ in a blocking solution $[0.05 \mathrm{M}$ Tris buffer $\mathrm{pH} 7.6$ (TBS), 0.3\% (v/v) Triton X-100 (Sigma), $10 \%(\mathrm{v} / \mathrm{v})$ normal goat serum (Saichi, Beijing, China), $5 \%(\mathrm{w} / \mathrm{v})$ bovine serum albumin [BSA (Sigma)] and incubated for $2 \mathrm{~h}$ at $37^{\circ} \mathrm{C}$ with primary IAA antibody (Agdia, Elkhart, IN) diluted 1:200 in TBST/BSA solution. Subsequently, sections were washed briefly in regular salt rinse solution [0.05 M TBS pH 7.6, $0.3 \%(\mathrm{v} / \mathrm{v})$ Triton X-100, 5\% (w/v) BSA], blocked out again, and incubated for $1 \mathrm{~h}$ at $37^{\circ} \mathrm{C}$ with the gold-labeled goat anti-mouse IgG (10-nm diameter) diluted 1:50 in TBS/BSA solution. After washing, the sections were submitted to the silver-enhancement reaction in a staining solution $[0.1 \mathrm{M}$ citrate buffer ( $\mathrm{pH} 3.5), 1.7 \%(\mathrm{w} / \mathrm{v})$ hydroquinone, $0.1 \%(\mathrm{w} / \mathrm{v})$ silver nitrate, $5 \%(\mathrm{w} / \mathrm{v})$ acacia]. As the color developed (20 $\min )$ on the sections, they were rinsed twice in water, dehydrated through a series of ethanol steps $(70 \%, 85 \%, 95 \%$, $100 \%$ ), mounted, observed, and photographed using a microscope (Olympus) (Fig. 3).

Negative CONTROLs. First, EDC was omitted during prefixation; second, the primary IAA antibody was omitted; and third, the secondary IAA antibody was omitted. All other procedures were performed as usual. Three replicates were used for each sampling (Fig. 4).

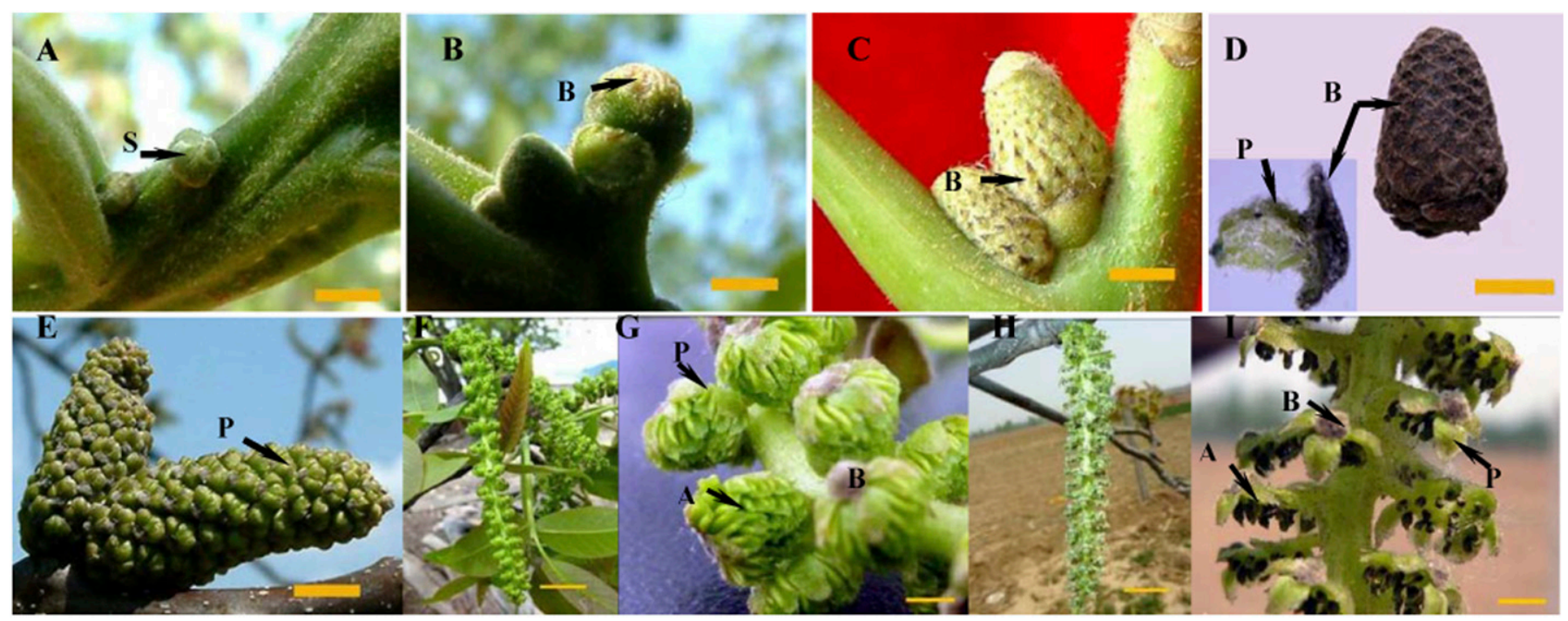

Fig. 1. External morphology of walnut staminate catkins: $\mathbf{A}-\mathbf{F}$ and $\mathbf{H}$ are the seven stages of staminate flower. (A) Stage 1, the catkins were oblate, only squama externally visible. (B) Stage 2, the catkins began to elongate and the bract became externally visible. (C) Stage 3, the bracts were visible and getting brown. (D) Stage 4, the bracts were brown and wrapped tightly. (E) Stage 5, the perianth became visible externally. (F) Stage 6, the anthers became visible and exhibited a yellowish tinge. (H) Stage 7, the anther dehisced, and turned black. Images $\mathbf{G}$ and $\mathbf{I}$ are the magnification of $\mathbf{F}$ and $\mathbf{H}(\times 5)$, respectively; A=anther, B = bract, $\mathrm{P}=$ perianth, $\mathbf{S}=$ squamas; bar $=0.4 \mathrm{~cm}(\mathbf{A}-\mathbf{E}, \mathbf{G}, \mathbf{I})$, bar $=2 \mathrm{~cm}(\mathbf{F}, \mathbf{H})$. 

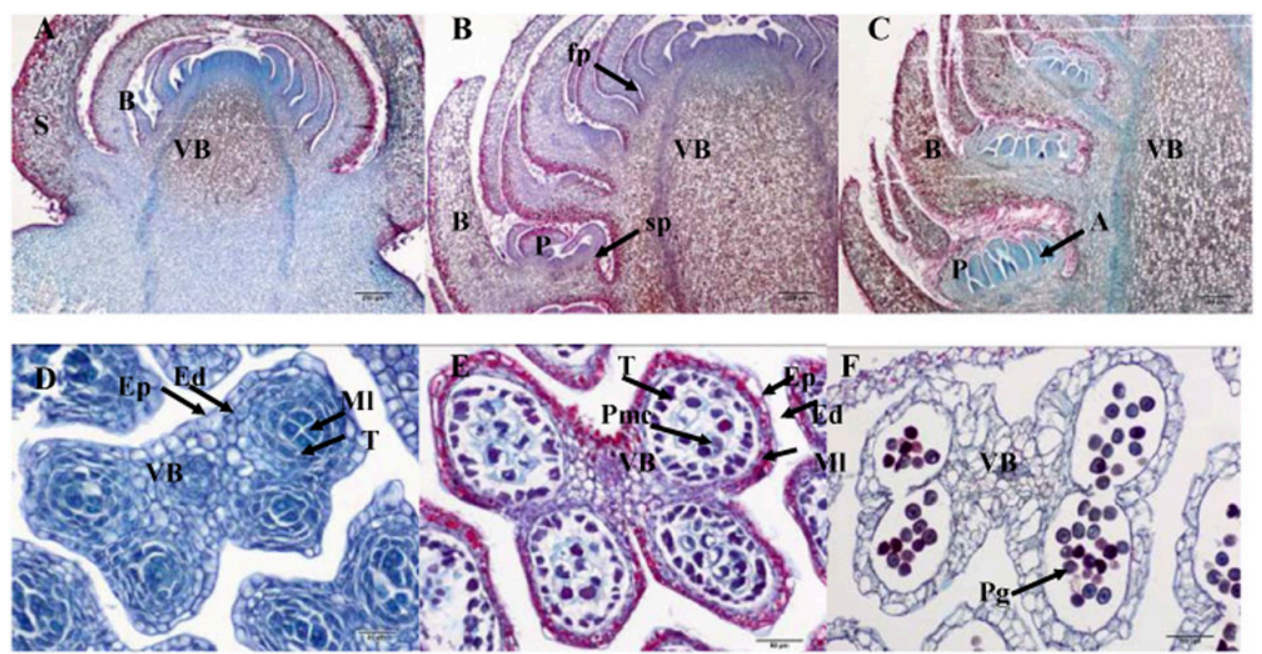

Fig. 2. The anatomy of walnut staminate flowers: A-C, the longitudinal sections of staminate catkin. (A) Stage 1, several bract primordia were present in the squama. (B) Stage 2, the floret, perianth, and stamen primordia formed basipetally. (C) Stage 3, stamen primordia formed gradually. D-F, The cross-sections of anther. (D) Stage 4, cellular specialization occurred to form a central core containing reproductive cells and tapetal cells that differentiated. (E) Stage 5, reproductive cells and tapetal cells separated from the exterior layers of the anther wall. (F) Stage 6, the anther walls were reduced to two cell layers and began to break; $\mathrm{A}=$ anther, $\mathrm{Ac}=$ archesporial cell, $\mathrm{B}=$ bract, $\mathrm{Ed}=$ endothecium, $\mathrm{Ep}=$ epidermis, $\mathrm{fp}=$ flower primordium, $\mathrm{Ml}=$ middle layer, $\mathrm{P}=$ perianth, $\mathrm{Pg}=$ pollen grain, $\mathrm{Pmc}=$ pollen mother cell, $\mathrm{Pc}=$ parietal cell, $\mathrm{Sc}=$ sporogenous cell, $\mathrm{S}=$ squamas, $\mathrm{sp}=$ stamen primordium, $\mathrm{T}=$ tapetum, $\mathrm{VB}=$ vascular bundle; $\mathrm{bar}=200 \mu \mathrm{m}(\mathbf{A}-\mathbf{C}), \mathrm{bar}=20 \mu \mathrm{m}(\mathbf{D})$, bar $=50 \mu \mathrm{m}(\mathbf{E})$, bar $=$ $100 \mu \mathrm{m}(\mathbf{F})$.
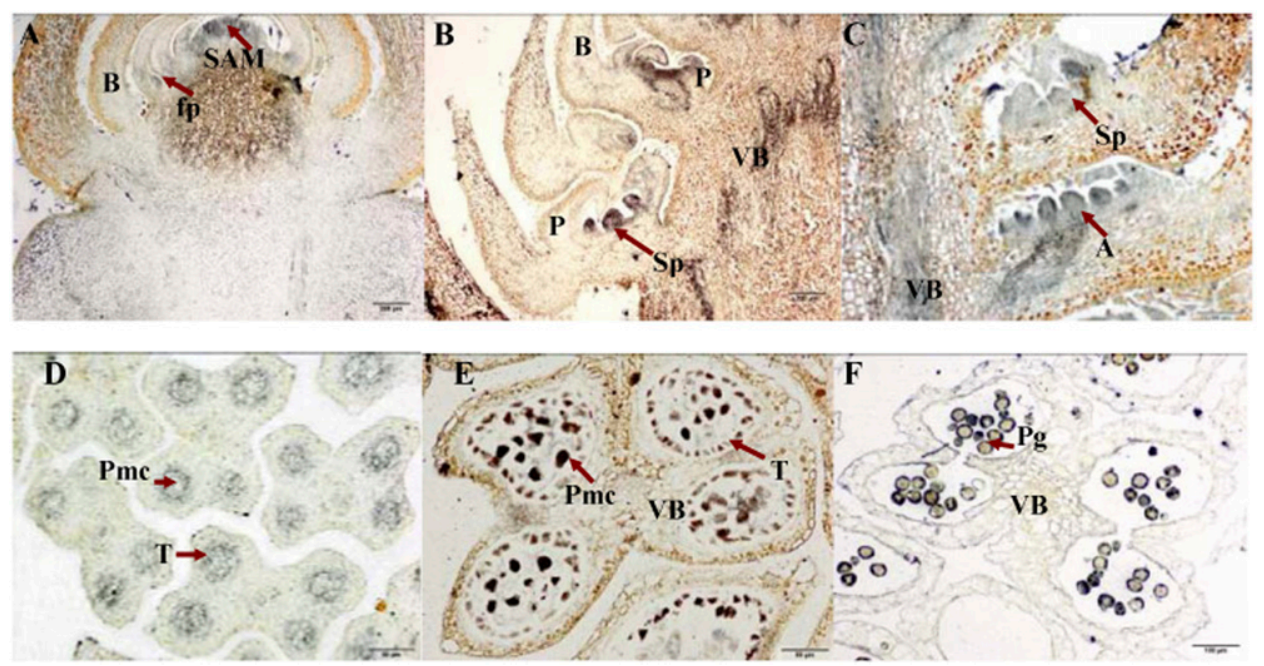

Fig. 3. Indole acetic acid (IAA) immunolocalization of walnut stamens: (A) longitudinal sections of staminate catkin during bract differentiation ( $\mathrm{bar}=200 \mu \mathrm{m}$ ), high levels of IAA signals were observed around shoot apical meristem and flower primordium. (B) Longitudinal sections of staminate catkin during perianth and stamen primordium differentiation ( $\mathrm{bar}=200 \mu \mathrm{m}$ ). (C) Longitudinal sections of staminate catkin during stamen differentiation ( $\mathrm{bar}=100 \mu \mathrm{m}$ ). IAA is distributed mainly in the stamen primordium and vascular bundles and little occurs in the bract. (D-F) The growth structure of anther, the levels of IAA were higher in pollen mother cells than other tissues $(\mathrm{bar}=50 \mu \mathrm{m}) ; \mathrm{Ac}=$ archesporial cell, $\mathrm{B}=$ bract, $\mathrm{fp}=$ flower primordium, $\mathrm{P}=$ perianth, $\mathrm{Pc}=$ parietal cell, $\mathrm{Pmc}=$ pollen mother cell, $\mathrm{SAM}=$ shoot apical meristem, $\mathrm{Sc}=$ sporogenous cell, $\mathrm{Gp}=$ germ pores, $\mathrm{sp}=$ stamen primordium, $\mathrm{T}=$ tapetum, $\mathrm{VB}=$ vascular bundle; arrows indicate the locations of IAA.

INDOLE-3-ACETIC ACID SEMIQUANTITATIVE ANALYSIS. The distribution of IAA during catkin differentiation in walnut was revealed by reddish brown silver particles in stained sections. For each tissue, 30 oil immersion light micrographs $(100 \times$ objective lens, $10 \times$ ocular lens) were taken at each stage of walnut catkin differentiation. Using the image analysis software Image-Pro Plus6.0 (Media Cybernetics, Silver Spring,
MD), we searched for silver particles, counted the number of unit areas, and then analyzed the distribution of IAA in different developing parts. The labeling density is presented as the number of silver

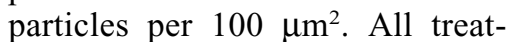
ments were repeated at least three times, and all samples were analyzed three times. Analysis of variance was performed, and significant differences between pairs of means were determined using a multiplerange test. Significance was assumed at $P<0.05$.

\section{Results}

Morphologic observation. Seven distinct morphologic stages were recognized for 'Liaoning 1' and 'Liaoning 3' (Fig. 1) based on the following markers: bract and anther color and external visibility of the bract, perianth, anthers, and rachis (Table 1). The various stages of catkin morphology were divided based on changes in length and shape. The catkins were oblate and enwrapped in squamae in Stage 1 (Fig. 1A). The major distinguishing feature of Stage 2 to 4 catkins was that the bracts were so tightly attached to the rachis that neither the perianths nor the anthers were externally visible. These stages could be distinguished based on the length and color of the bracts. For example, the green bracts gradually turned brown, and the surface of individual staminate flowers appeared white and villous (Fig. 1D). The perianths and anthers were obvious by external examination and the length of the catkins increased in Stage 5. Stage 6 anthers exhibited a yellowish tinge, and the angle between the perianth and the catkin rachis was $\approx 90^{\circ}$ (Fig. 1G). Those anthers exposed to the sun below the midpoint of the catkin dehisced first, and the anthers become black and dehydrated in Stage 7 (Fig. 1I). The entire process from Stage 1 to Stage 7 lasted $\approx 1$ year.

MORPHOlOgicAl MODIFICATIONS RELATED TO VARIOUS HISTOLOGICAL CHARACTERISTICS. Morphological markers are effective tools for estimating variation in histogenesis. In Stage 1, only the squamae were visible externally and the catkins were oblate (Fig. 1A). However, anatomic observation revealed that the bract primordium had developed (Fig. 2A). Each catkin included more than one differentiation stage from 
Stage 1 to Stage 4 . As the length of each catkin increased, a red bract was visible (Fig. 1B). At this stage, floret, perianth, and stamen primordia were observed basipetally (Fig. 2B). In Stage 3 , the catkin increased in length and the development of the bract ended. Simultaneously, stamen differentiation began in the interior of the catkin (Fig. 2C). The anthers differentiated continuously in Stage 4. The parietal cells split horizontally several times, and the endothecium, middle layer, and tapetum formed when the bract became dark yellowish brown (Fig. 2D). As the temperature fell in fall, the bracts became brown and semilignified (Fig. 1D). In anther cross-sections (Fig. 2D), sporogenous cells were observed in the center of each locule, which was surrounded by a single layer of elongated tapetal cells; these sporogenous cells split to form pollen mother cells. In the spring of Stage 5, the catkins elongated and perianths were visible, whereas the middle layers were compressed (Figs. $1 \mathrm{E}$ and $2 \mathrm{E}$ ). Once the anthers were visible externally in Stage 6, the tapetal cells surrounding the reproductive cells were found

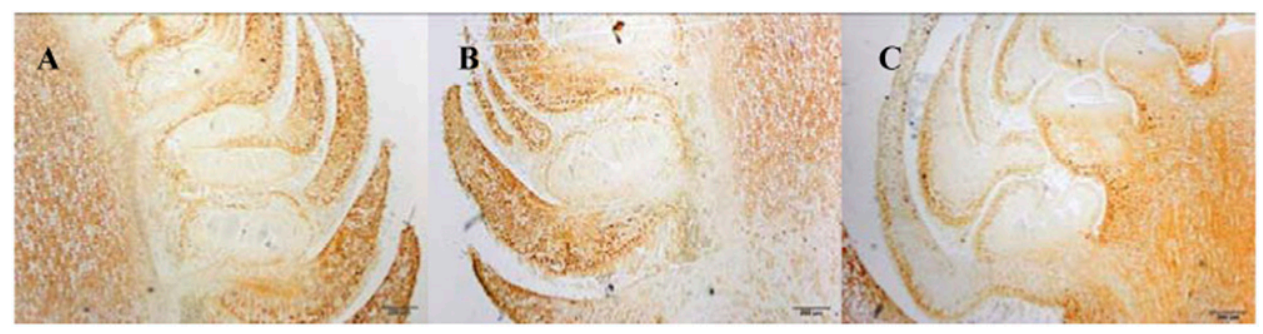

Fig. 4. Controls of walnut staminate flower indole acetic acid (IAA) immunolocalization: (A) longitudinal sections of staminate catkin stained without 1-ethyl-3-(3-dimethylaminopropyl) carbodiimide (EDC), there is a low level of IAA (bar $=200 \mu \mathrm{m})$. (B-C) Longitudinal sections of staminate catkin stained omitting primary antibody and secondary antibody; IAA was not shown almost $($ bar $=200 \mu \mathrm{m})$. to have disintegrated and the pollen grains matured (Figs. 1F and 2F). Changes in morphology can be used to monitor changes in histological characteristics.

RELATIONSHIP BETWEEN THE IN SITU AUXIN LEVEL AND FLORAL HISTOLOGY. The distribution of auxin throughout the floral differentiation period was investigated using monoclonal antiauxin antibodies (Fig. 3). During differentiation of the bract and floret primordia, auxin was distributed mainly in the SAM (several organized layers of cells) and staminate flower primordium (Fig. 3A). The density of silver particles was 80.8 and 110.4 particles per $100 \mu \mathrm{m}^{2}$, respectively (Fig. 5A). The density of silver particles in the bract was 11.4 particles per $100 \mu \mathrm{m}^{2}$ (Fig. 5B), lower than that in primordium cells. Next, the perianth and stamen primordia formed. Auxin was present in these differentiated tissues (Fig. 3B). The density of silver particles was 76.9 and 93.5 particles per $100 \mu \mathrm{m}^{2}$. The stamen primordium had a high level of auxin, which persisted into the later stages of development (Figs. 3C and 5B). The endothecium, middle layer, and tapetum formed after division of the parietal cells. Auxin was concentrated in the tapetum and pollen mother cells, which were derived from sporogenous cells (Fig. 3D). In the spring, the flower bud resumed differentiation. Auxin was still concentrated in the tapetum and pollen mother cells (Fig. 3E). The cells of the tapetum degenerated gradually. At this time, auxin was distributed mainly in the pollen grains and on the pollen grain surface on sprouting (Fig. 3F). Throughout this process, the vascu-

Table 1. Morphological characterization of catkin development in walnut.

\begin{tabular}{cccccccc}
\hline & \multicolumn{7}{c}{ Catkin characteristic } \\
Catkin stage & Bract color & Bract visible & Perianth visible & Anther visible & Rachis visible & Anther color & Season \\
\hline 1 & - & No & No & No & No & - & Spring \\
2 & Red & Yes & No & No & No & Green & Spring \\
3 & Green & Yes & No & No & No & Green & Summer \\
4 & Brown & Yes & No & No & No & Green & Autumn, winter \\
5 & Brown & Yes & Yes & Yes & No & Green & Spring \\
6 & Brown & Yes & Yes & Yes & Yes & Yellow & Spring \\
7 & Brown & Yes & Yes & Dehiscence & Yes & Black & Spring \\
\hline
\end{tabular}

A

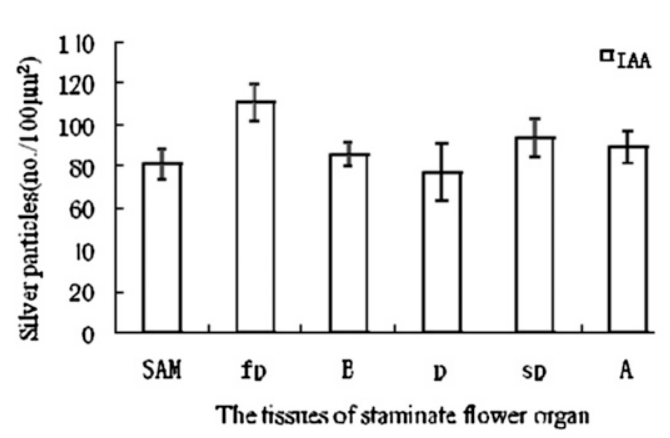

B

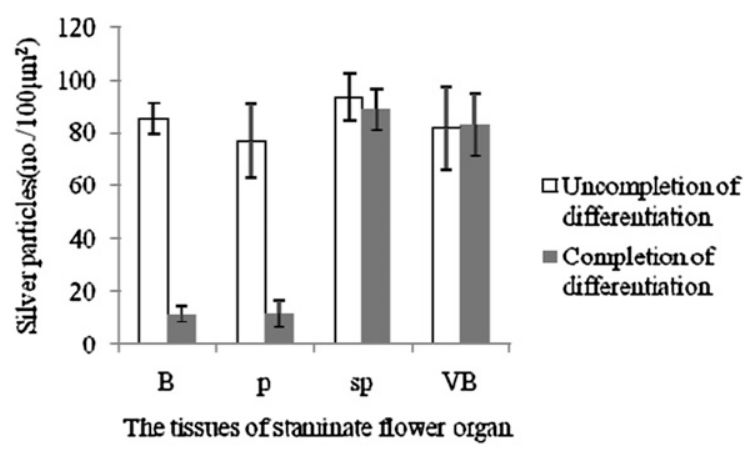

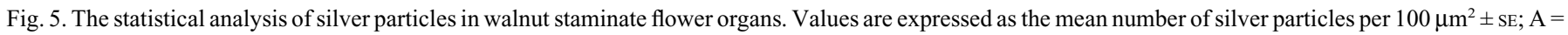
anther, $\mathrm{B}=$ bract, $\mathrm{fp}=$ flower primordium, $\mathrm{P}=$ perianth, $\mathrm{SAM}=$ shoot apical meristem, $\mathrm{sp}=$ stamen primordium, $\mathrm{VB}=$ vascular bundle. 
lar bundles in the rachis contained high levels of auxin (Fig. $3 \mathrm{~A}-\mathrm{C}$ ), although the vascular bundles in the anthers maintained low levels. Therefore, we speculated the level of auxin may play an important role in regulating walnut staminate flower differentiation.

Auxin was present in the staminate flowers throughout their differentiation. We verified the effectiveness of our immunolocalization technique and the specificity of the antibody with several control procedures. Because the monoclonal antibody was raised against free auxin crosslinked to bovine serum albumin through its carboxyl group (Leverone et al., 1991), we tested unfixed tissues for the silver development reaction. Small silver particles comparable to those in prefixed longitudinal sections (Fig. 4A) developed, indicating that prefixation with 1ethyl-3-[3-dimethylaminopropyl] carbodiimide hydrochloride is essential for the detection of free auxin using this antibody. When the primary (Fig. 4B) or secondary antibody (Fig. 4C) was omitted, no signal was observed, suggesting that the silver development reaction was dependent on the presence of these antibodies in the tissue sections.

\section{Discussion}

Individual staminate flowers are small and relatively inconspicuous. Grouped, they are arranged in hanging clusters called catkins, which develop laterally on the previous season's growth. Histological analyses of staminate flowers have been done previously (Li et al., 2011; Luza and Polito, 1988). The present study shows that the external morphology of staminate flowers is a marker for judging changes in histological structure (Figs. 1 to 4 ). This will provide a scientific basis for the study of catkins. Furthermore, understanding the differentiation of staminate flowers in walnut will be useful in designing a reasonable configuration for tree pollination and catkin thinning. Based on our results, we believe that the best period for thinning staminate flowers is before budbreak; however, this would require many workers and a lot of time. In this article, an immunohistochemical method was used to study the in situ distribution of auxin during staminate flower differentiation. Our results indicate that the level of auxin is high during staminate flowers initially (Fig. 3A).

The present study shows that the morphological characteristics of walnut catkins could be divided into seven stages based on the visibility of various organs (Fig. 1). The histological changes observed in staminate flowers include the floret primordium, bract, perianth, and stamen differentiation periods (Fig. 2). This result is similar to that in previous studies ( $\mathrm{Li}$ et al., 2011; Luza and Polito, 1988). During the differentiation process, auxin was more concentrated in tissues undergoing differentiation. During anther formation, auxin was mainly distributed in the tapetum and pollen mother cells until the pollen matured (Fig. 3D-E). This result is similar to that of Valentina et al. (2008), whose investigation suggested that auxin synthesized in the anthers plays a major role in coordinating anther dehiscence and pollen maturation, whereas auxin transport contributes to the independent regulation of preanthesis filament elongation. In addition, the relationship among morphological characteristics, physiology, and histology was established. We can judge the histological and physiological characteristics of staminate flowers based on their morphology.

Much research has been done on auxin, including studies of its physiological role, site of synthesis, and transport route.
Auxin plays an important role in flower differentiation and development (Aloni et al., 2006; Cheng and Zhao, 2007). It also helps regulate the sex of flowers. A study of cactus (Opuntia stenopetala) plants showed that high levels of auxin promote the formation of gynoecia (Gregorio et al., 2012). However, the site of synthesis and route of transport for auxin remain to be clarified. The shoot apex has been considered to be the site of auxin synthesis (Bartel, 1997), but a different site has also been proposed (Orna et al., 2002). According to this newer view, auxin is transported to the SAM rather than produced there. Auxin transport may promote flowering, as shown in a study of the arabidopsis mutant pin-1 (Oka et al., 1999). Heisler et al.'s (2005) study provided new insight into the dynamics of auxin transport during positioning of the primordia and suggested a role for auxin transport in influencing primordia cell type. Recently, auxin transport during organogenesis was studied in arabidopsis (Banasiak, 2011). The results of that study suggest the presence of at least two pathways of acropetal auxin transport: a superficial path through polar auxin transport and a second putative one through the vascular system. Organogenesis can be completely blocked only when both pathways are dysfunctional. During walnut staminate flower differentiation, the vascular bundles of the rachis contained high levels of auxin. Thus, the rachis may provide a transport pathway. In this study, we determined the temporal and spatial distribution of IAA during staminate flower differentiation in walnut. This is a basis for further study of IAA production sites and transport pathways.

\section{Literature Cited}

Aloni, R., E. Aloni, M. Langhans, and C.I. Ullrich. 2006. Role of auxin in regulating arabidopsis flower development. Planta 223:315-328.

Aloni, R.K., M. Schwalm, and C.I. Langhans. 2003. Gradual shifts in sites of free-auxin production during leaf-primordium development and their role in vascular differentiation and leaf morphogenesis in arabidopsis. Planta 216:841-853.

Banasiak, A. 2011. Putative dual pathway of auxin transport in organogenesis of arabidopsis. Planta 233:49-61.

Bartel, B. 1997. Auxin biosynthesis. Annu. Rev. Plant Physiol. Plant Mol. Biol. 48:51-66.

Chandler, J.W. 2011. The hormonal regulation of flower development. J. Plant Growth Regul. 30:242-254.

Cheng, Y.F. and Y.D. Zhao. 2007. A role for auxin in flower development. J. Integr. Plant Biol. 49:99-104.

Cristiana Moliterni, V.M., L. Cattivelli, P. Ranalli, and G. Mandolino. 2004. The sexual differentiation of Cannabis sativa L.: A morphological and molecular study. Euphytica 140:95-106.

Dong, N.G., W.L. Yin, Y. Gao, and D. Pei. 2012. Indole-3-acetic acid accumulation during poplar rhizogenesis revealed by immunohistochemistry. Biol. Plant. 56:581-584.

Fu, X.X., L. Feng, X.L. Shang, W.X. Yang, and S.Z. Fang. 2011. Observation of morphological and anatomical characters on staminate and pistillate flower differentiation in Cyclocarya paliuru. J. Nanjing For. Univ. (Natural Sci. Ed.) 35:17-22.

Gregorio, O.A., V.S. Sonia, C. Aldebaran, G.D. Joseph, and C.G. Felipe. 2012. Inception of maleness: Auxin contribution to flower masculinization in the dioecious cactus Opuntia stenopetala. Planta 236:225-238.

He, Y.H., S.Q. Fang, Z.Y. Hu, J. Ma, J. Luo, C.H. Wu, L. Cao, M. Lu, and C.J. Chen. 2012. Morphological and anatomical analysis of pineapple somatic embryogenesis. Acta Hort. Sinica 39:57-63.

Heisler, M.G., C. Ohno, P. Das, P. Sieber, G.V. Reddy, J.A. Long, and E.M. Meyerowitz. 2005. Patterns of auxin transport and gene expression during primordium development revealed by live imaging of the arabidopsis Inflorescence meristem. Curr. Biol. 15:1899-1911. 
Holgate, C.S., P. Jackson, and P.N. Cowen. 1983. Immunogold silver staining: New method of immunostaining with enhanced sensitivity. J. Histochem. Cytochem. 7:938-944.

Hou, Z.X. and W.D. Huang. 2005. Immunohistochemical localization of IAA and ABP1 in strawberry shoot apexes during floral induction. Planta 222:678-687.

Jiménez, V.M. 2005. Involvement of plant hormones and plant growth regulators on in vitro somatic embryogenesis. Plant Growth Regulat. 47:91-110.

Leverone, L.A., T.L. Stroup, and J.L. Caruso. 1991. Western blot analysis of cereal grain prolamins using an antibody to carboxyllinked indoleacetic acid. Plant Physiol. 96:1076-1078.

Li, Y.T., Y.G. Zhao, K.Q. Yang, Y.Y. Fang, and L.Q. Hou. 2011. Studies on floral organ development process of precocious walnut (juglans regia) by anatomia. Acta Hort. Sinica 38:434-440.

Luza, J.G. and V.S. Polito. 1988. Microsporogenesis and anther differentiation in Juglans regia L.: A developmental basis for heterodichogamy in walnut. Bot. Gaz. 149:30-36.

Marleen, V. and B. Eva. 2012. Hormonal Interactions in the regulation of plant development. Annu. Rev. Cell Dev. Biol. 28:22.1-22.25.

Oka, M., K. Miyamoto, K. Okada, and J. Ueda. 1999. Auxin polar transport and flower formation in arabidopsis thaliana transformed with indoleacetamide hydrolase (IAAH) gene. Plant Cell Physiol. 40:231-237.
Orna, A.K., J.C. Cheng, L.J. Chen, E. Moctezuma, and Z.R. Sung. 2002. Indole acetic acid distribution coincides with vascular differentiation pattern during arabidopsis leaf ontogeny. Plant Physiol. 130:199-209.

Polito, V.S. and P. Katherine. 1997. The relationship between phenology of pistillate flower organogenesis and mode of heterodichogamy in Juglans regia L. (Juglandaceae). Sex. Plant Reprod. 10:36-39.

Valentina, C., M.A. Maria, F. Giuseppina, C. Paolo, and C. Maura. 2008. Auxin regulates arabidopsis anther dehiscence, pollen maturation, and filament elongation. Plant Cell 20:1760-1774.

Vladimra, L. and Z. Sladky. 1971. The role of growth regulators in the differentiation of walnut buds (Juglans regia L.). Biol. Plant. 13:361-367.

Vysotskaya, L.B., S.Y. Veselov, D.S. Veselov, V.N. Filippenko, E.A. Ivanov, I.I. Ivanov, and G.R. Kudoyarova. 2007. Immunohistological localization and quantification of IAA in studies of root growth regulation. Russ. J. Plant Physiol. 54:827-832.

Woodward, A.W. and B. Barrel. 2005. Auxin: Regulation, action, and interaction. Ann. Bot. (Lond.) 95:707-735.

Yates, I.E. and D. Sparks. 1992. External morphological characteristics for histogenesis in pecan anthers. J. Amer. Soc. Hort. Sci. 117:181-189.

Zhang, Z.H., W.J. Wang, Y. Gao, and G.Q. Du. 1995. The process of flower differentiation on dichogamy of walnut. Acta Hort. Sinica 22:391-393. 